\title{
Modeling the trade-off between diet costs and methane emissions: A goal programming approach
}

\author{
L. E. Moraes, ${ }^{*}$ J. G. Fadel,, ${ }^{*}$ A. R. Castillo,† D. P. Casper,ł J. M. Tricarico,§ and E. Kebreab*1 \\ *Department of Animal Science, University of California, Davis 95616 \\ †Cooperative Extension, University of California, Merced 95341 \\ ‡Dairy Science Department, South Dakota State University, Brookings 57007 \\ §Innovation Center for US Dairy, Rosemont, IL 60018
}

\begin{abstract}
Enteric methane emission is a major greenhouse gas from livestock production systems worldwide. Dietary manipulation may be an effective emission-reduction tool; however, the associated costs may preclude its use as a mitigation strategy. Several studies have identified dietary manipulation strategies for the mitigation of emissions, but studies examining the costs of reducing methane by manipulating diets are scarce. Furthermore, the trade-off between increase in dietary costs and reduction in methane emissions has only been determined for a limited number of production scenarios. The objective of this study was to develop an optimization framework for the joint minimization of dietary costs and methane emissions based on the identification of a set of feasible solutions for various levels of tradeoff between emissions and costs. Such a set of solutions was created by the specification of a systematic grid of goal programming weights, enabling the decision maker to choose the solution that achieves the desired tradeoff level. Moreover, the model enables the calculation of emission-mitigation costs imputing a trading value for methane emissions. Emission imputed costs can be used in emission-unit trading schemes, such as cap-and-trade policy designs. An application of the model using data from lactating cows from dairies in the California Central Valley is presented to illustrate the use of modelgenerated results in the identification of optimal diets when reducing emissions. The optimization framework is flexible and can be adapted to jointly minimize diet costs and other potential environmental impacts (e.g., nitrogen excretion). It is also flexible so that dietary
\end{abstract}

Received December 21, 2014.

Accepted March 7, 2015.

${ }^{1}$ Corresponding author: ekebreab@ucdavis.edu costs, feed nutrient composition, and animal nutrient requirements can be altered to accommodate various production systems.

Key words: environmental impact, methane, diet formulation, linear programming

\section{INTRODUCTION}

Dietary factors associated with methane $\left(\mathrm{CH}_{4}\right)$ emissions have been traditionally examined with the objective of determining nutritional characteristics associated with gaseous energy losses (Blaxter and Clapperton, 1965; Moe and Tyrrell, 1979). In recent years, research on $\mathrm{CH}_{4}$ emissions has been redirected to the reduction of greenhouse gas (GHG) emissions because $\mathrm{CH}_{4}$ emission from livestock production is an important GHG source worldwide. For instance, in $2012 \mathrm{CH}_{4}$ emissions from enteric fermentation accounted for $25 \%$ of total US $\mathrm{CH}_{4}$ emissions from anthropogenic sources (EPA, 2014). Although representative, it is important to point out that the agriculture sector as a whole is only responsible for $8.1 \%$ of total US GHG emissions, and its main contributor is agricultural soil management (EPA, 2014). In this context, several studies have been conducted to identify and review technical options for mitigating $\mathrm{CH}_{4}$ emissions (e.g., Boadi et al., 2004; Martin et al., 2010; Gerber et al., 2013; Hristov et al., 2013), and dietary manipulation has been suggested as a key mitigation tool (Kebreab et al., 2010). Recently, interest has increased on practical aspects related to the implementation of mitigation strategies and also on the associated mitigation costs (e.g., Doreau et al., 2014; Pacheco et al., 2014). Mathematical models play a major role in the determination of costs associated with $\mathrm{CH}_{4}$ mitigation and also in the investigation of the compromise between reducing $\mathrm{CH}_{4}$ emissions and increased mineral and nitrogen excretion (Moraes et al., 2012; Dijkstra et al., 2013; Sauvant et al., 2014). 
Several models have been developed to predict $\mathrm{CH}_{4}$ emissions from various classes of animals and to identify central processes in the ruminal digestion of carbohydrates that may be altered to mitigate emissions (Moe and Tyrrell, 1979; Baldwin, 1995; Kebreab et al., 2004; Moraes et al., 2014). However, only a limited number of studies have examined the application of decisionmaking models for mitigating $\mathrm{CH}_{4}$ emissions from dairy systems through dietary manipulation.

Mathematical programming models have been used to optimize the use of scarce resources in various economic sectors (e.g., Dantzig, 1963; Kennedy, 1986). In the livestock industry, such models have been mostly developed to optimize diets (St-Pierre and Harvey, 1986; Tedeschi et al., 2000), to examine optimal policies in reproductive-management programs (De Vries, 2006; Giordano et al., 2012), and to identify optimal animalreplacement strategies (Kristensen, 1992; Nielsen et al., 2010). The application of decision-making models to improve the sustainability of the livestock industry has frequently focused on minimizing and managing mineral and nitrogen balance and excretion. For instance, Jean dit Bailleul et al. (2001) and Pomar et al. (2007) modified the least cost diet algorithm to minimize nitrogen and phosphorus excretion by pigs. Dubeau et al. (2011) proposed multicriteria programming models to reduce nitrogen and phosphorus excretion by pigs based on the observation that a trade-off existed between diet cost and environmental impacts of pig production. Moreover, Cabrera (2010) developed a Markovian model to optimize replacement policies and dairy-herd net income for diets and nitrogen excretion. The demand for these optimization models is driven by the increase in the establishment of environmental policies regulating the livestock industry (Oenema, 2004). In California, a cap-and-trade system to reduce GHG emissions has already been implemented by the California Air Resources Board (CARB, 2008). The potential application of a cap-and-trade policy scheme to the dairy industry was examined by Moraes et al. (2012), who showed that mitigating $\mathrm{CH}_{4}$ emissions from US dairy cows by dietary manipulation may be expensive. The same authors advocated that optimization models may assist dairy producers when complying with $\mathrm{CH}_{4}$-emission regulatory policies in an optimal manner. Therefore, the objective of this study was to develop an optimization framework for the joint minimization of dietary costs and $\mathrm{CH}_{4}$ emissions through the identification of the set of feasible solutions for various levels of trade-offs between dietary costs and emissions. This framework extends the model from Moraes et al. (2012) and provides the decision maker the opportunity to select the most desired solution according to current feed prices and policy regulations.

\section{MATERIALS AND METHODS}

\section{General Framework}

The model was structured in 3 sequential parts. In the first part, an equation was developed to predict $\mathrm{CH}_{4}$ emissions from lactating dairy cows using a large database of indirect calorimetry records. In the second part, 2 linear programming models were developed and solved for the individual minimization of dietary costs and $\mathrm{CH}_{4}$ emissions. In the third part, a weighted goal programming model was developed and solved for the joint minimization of diet costs and $\mathrm{CH}_{4}$ emissions from lactating dairy cows. The $\mathrm{CH}_{4}$ prediction equation from the first part was used in both the linear programming and goal programming models. Likewise, the 2 linear programming models were used to determine the targets and goal constraints in the goal programming model.

\section{Prediction of Methane Emissions}

The objective of this section was to develop a model that could predict $\mathrm{CH}_{4}$ emissions from lactating dairy cows and could be directly adapted to a constraint equation or objective function from a linear programming model. The main assumptions of linear programming models are proportionality and additivity (Winston and Venkataramanan, 2002). The proportionality assumption requires that the contribution of each decision variable to the objective function or constraint is proportional to the value of the variable itself. Similarly, the additivity assumption requires that the contribution of each decision variable is independent of the value of the other variables (Winston and Venkataramanan, 2002). The prediction model was therefore developed using nutrient intakes as independent variables because those would result in a model with proportional and additive decision variables representing intakes of feeds. A systematic and sequential model-selection strategy was used to identify the independent variables that were fundamental in predicting $\mathrm{CH}_{4}$ emissions. First, all possible models resulting from the use of NDF, ether extract (EE), CP, and ME intakes as independent variables were constructed, and the condition indexes of the design matrices were determined with the perturb package in the software R (Hendrickx, 2012). Models for which the largest index was greater than 10 were discarded because possible issues with multicollinearity arise when the condition number is between 10 and 30 and the presence of multicollinearity is severe when the condition number is greater than 30 (Belsley et al., 1980). The remaining models were fitted, and the model with the smallest deviance information criterion was selected (Spiegelhalter et al., 2002). 
The data used for model development were from the database of lactating cows described by Moraes et al. (2014). Multiple records on the database originated from the same animal and were grouped into various studies. A mixed effects model was therefore used to represent the correlation between observations from the same animal and study. Linear mixed effects models have a natural representation as Bayesian hierarchical models (Jiang, 2007). Furthermore, previous analysis of these data suggested the presence of outlying $\mathrm{CH}_{4}$ emissions records (Moraes et al., 2014). Therefore, the models were fitted with a Student's $t$ distribution for the observations providing robustness to outlying observations. Specifically, we implemented the model as a 3-stage Bayesian hierarchical model for which the firststage hierarchy specified a model for the data given the location parameters $\boldsymbol{\beta}, \boldsymbol{\alpha}_{i}, \boldsymbol{\gamma}_{j}$; the dispersion parameter $\tau$; and the degrees of freedom parameter $\nu$ :

$$
y_{i j k} \mid \boldsymbol{\beta}, \boldsymbol{\alpha}_{i}, \gamma_{j}, \tau, \nu \sim t\left(\mathbf{x}_{i j k}^{\mathrm{T}} \boldsymbol{\beta}+\mathbf{z}_{1 i j k}^{\mathrm{T}} \boldsymbol{\alpha}_{i}+\mathbf{z}_{\mathbf{2} i j k}^{\mathrm{T}} \boldsymbol{\gamma}_{j}, \tau, \nu\right),
$$

where $\mathrm{T}$ denotes the transpose of a matrix or vector, $y_{i j k}$ is $k$ th record $\left(k=1, \ldots, n_{i j}\right)$ on the $i$ th animal $(i$ $=1, \ldots, I)$ in the $j$ th study $(j=1, \ldots, J), \boldsymbol{\beta}$ is the $p$ $\times 1$ vector of fixed regression coefficients, $\boldsymbol{\alpha}_{i}$ is the $p$ $\times 1$ vector of random regression coefficients associated with the $i$ th animal, $\boldsymbol{\gamma}_{j}$ is the $p \times 1$ vector of random regression coefficients associated with the $j$ th study, $\mathbf{x}_{i j k}$ is the $p \times 1$ covariate vector for the fixed effects, and $\mathbf{z}_{1 i j k}$ and $\mathbf{z}_{2 i j k}$ are $p \times 1$ covariate vectors for the random effects. Furthermore, $t(\mu, \tau, \nu)$ is the Student's $t$ distribution with density

$$
f(x)=\frac{\Gamma\left(\frac{v+1}{2}\right)}{\Gamma\left(\frac{v}{2}\right)} \sqrt{\frac{\tau}{v \pi}}\left[1+\frac{\tau}{v}(x-\mu)^{2}\right]^{-(v+1) / 2} .
$$

In this notation, $\Gamma($.$) represents the gamma function.$ In this notation, $\mu$ represents the mean and $\pi$ the $\pi$ number. The second-stage hierarchy specified the distribution of the random effects given their variance components. Random effects were assumed to be mutually independent and distributed as

$$
\begin{cases}\boldsymbol{\alpha}_{i} \mid \boldsymbol{\Omega}_{1} \sim N\left(\mathbf{0}, \boldsymbol{\Omega}_{\mathbf{1}}\right), & i=1, \ldots, I \\ \gamma_{j} \mid \Omega_{2} \sim N\left(\mathbf{0}, \Omega_{2}\right), & j=1, \ldots, J\end{cases}
$$

where $N\left(\mathbf{0}, \Omega_{1}\right)$ and $N\left(\mathbf{0}, \Omega_{2}\right)$ are $p$ th dimensional multivariate Gaussian densities centered at zero and with precision matrices $\boldsymbol{\Omega}_{1}$ and $\boldsymbol{\Omega}_{2}$ of order $p$. These
Gaussian densities are parameterized in terms of the precision matrix for which $N(\boldsymbol{\mu}, \boldsymbol{\Omega})$ has density $f(\boldsymbol{x})=$ $(2 \pi)^{-p / 2}|\boldsymbol{\Omega}|^{1 / 2} \exp \left[-1 / 2(\boldsymbol{x}-\boldsymbol{\mu})^{\mathrm{T}} \boldsymbol{\Omega}(\boldsymbol{x}-\boldsymbol{\mu})\right]$. The thirdstage hierarchy specified prior distributions for the model parameters using minimally informative prior distributions (Gelman et al., 2004):

$$
\left\{\begin{array}{l}
\beta \sim N\left(\mathbf{0}, \mathbf{I}_{\mathbf{p}} 10^{-6}\right) \\
\boldsymbol{\Omega}_{\mathbf{1}} \sim \mathrm{W}\left(\mathbf{I}_{\mathbf{p}}, p\right) \\
\boldsymbol{\Omega}_{\mathbf{2}} \sim \mathrm{W}\left(\mathbf{I}_{\mathbf{p}}, p\right) \\
\tau \sim \operatorname{Gam}\left(10^{-3}, 10^{-3}\right) \\
v \sim \text { Uniform }(2,100)
\end{array},\right.
$$

where $N\left(\mathbf{0}, \mathbf{I}_{\mathbf{p}} 10^{-6}\right)$ is a $p$ th dimensional multivariate Gaussian density, $\mathbf{0}$ is a $p \times 1$ vector of zeros, $\mathbf{I}_{\mathbf{p}}$ is the identity matrix of order $p ; \mathrm{W}(\mathbf{R}, \xi)$ is the Wishart distribution with density $f\left(\mathbf{X}_{p \times p}\right)=|\mathbf{R}|^{\xi / 2}|\mathbf{X}|^{(\xi-}$ ${ }_{p-1) / 2} \exp [-1 / 2 \operatorname{tr}(\mathbf{R X})]$, where $\operatorname{tr}(\mathbf{X})$ represents the trace of the matrix $\mathbf{X}, \mathbf{R}$ is the scale matrix and $\xi$ the degrees of freedom. Furthermore, $\operatorname{Gam}(r, \lambda)$ is the Gamma distribution with density $f(x)=\left[\lambda^{r} x^{r-1} \exp (-\right.$ $\lambda x)] /[\Gamma(r)]$, where $\lambda$ and $r$ are the rate and shape parameters, respectively. Uniform $(a, b)$ is the uniform distribution with density $f(x)=1 /(b-a), a \leq x \leq b$, where $a$ and $b$ are the parameters determining the distribution support. The use of these distributions in the third-stage hierarchy specifies minimally informative prior densities so the analysis is mostly influenced by the observed data. For example, using $\boldsymbol{\beta} \sim N\left(\mathbf{0}, \mathbf{I}_{\mathrm{p}} 10^{-6}\right)$ sets a prior density with small precision or large variance $\left(10^{6}\right)$. Therefore, the prior knowledge incorporated into the analysis is minimal because a large uncertainty is assigned in the distribution of $\boldsymbol{\beta}$.

The estimation was based on Markov Chain Monte Carlo methods in the OpenBugs software (Thomas et al., 2006), which was interfaced with $\mathrm{R}$ through the BRugs package (Ligges, 2013). Two chains with dispersed initial values were monitored through trace, correlation, and history plots for determination of convergence. The Gelman-Rubin diagnostic was further used to investigate chain convergence (Gelman and Rubin, 1992). The ability of the model in fitting the data was investigated by the root mean square error (RMSE), defined by RMSE $=\left(n^{-1}\|\mathbf{y}-\mathbf{X} \hat{\boldsymbol{\beta}}\|^{2}\right)^{1 / 2}$, and through diagnostics plots. In this notation, $n$ is the number of observations, $\mathbf{y}$ is the vector of observed $\mathrm{CH}_{4}$ emissions, $\mathbf{X}$ is the design matrix, $\hat{\boldsymbol{\beta}}$ is the vector of estimates of regression parameters, and $\|\cdot\|$ is the Euclidean norm of a vector. 
Table 1. Summary statistics describing the 39 dairies from Castillo et al. (2013) used in the linear and goal programming models

\begin{tabular}{lcccl}
\hline Item & Mean & Minimum & Maximum & SD \\
\hline Milk yield (kg/cow·d) & 31.2 & 20.4 & 43.4 & 5.2 \\
Milk fat (\%) & 3.58 & 2.97 & 4.25 & 0.19 \\
Milk protein (\%) & 3.08 & 2.90 & 3.33 & 0.10 \\
Milk lactose (\%) & 4.80 & 4.71 & 4.92 & 0.05 \\
DMI (kg of DM/cow.d) & 23.1 & 18.5 & 26.0 & 1.8 \\
Diet NDF (\% of DM) & 35.1 & 29.9 & 42.1 & 2.5 \\
Diet ether extract (\% of DM) & 4.5 & 2.4 & 7.3 & 0.9 \\
Diet CP (\% of DM) & 17.4 & 13.9 & 22.1 & 1.4 \\
\hline
\end{tabular}

\section{Linear Programming Models}

Two linear programming models were developed to individually minimize diet costs and $\mathrm{CH}_{4}$ emissions from lactating dairy cows. The first model is the traditional least cost diet model, and the second model is a modified version of the linear programming model proposed by Moraes et al. (2012) to minimize daily $\mathrm{CH}_{4}$ emissions based on nutrient intakes. Models were formulated to deliver nutrients to sustain the milk production levels from Castillo et al. (2013). Summary statistics describing the dairies from Castillo et al. (2013) are in Table 1. Daily nutrient requirements of animals and nutrient composition of feeds were calculated according to the NRC (2001) guidelines. Both linear programming models were solved in the lpSolve package of the software $\mathrm{R}$ (Buttrey, 2005).

Least Cost Diet Model. The least cost diet model was formulated to minimize diet costs while delivering nutrients to sustain a given level of milk production. The model objective function and constraints are described as follows:

$$
\min z_{1}=\sum_{j=1}^{n} c_{j} x_{j}
$$

subject to

$$
\begin{gathered}
\sum_{j=1}^{n} a_{i j} x_{j} \geq b_{i}, i=1, \ldots, m, \\
u_{i} \leq \frac{\sum_{j=1}^{n} x_{j} \varphi_{i j}}{\sum_{j=1}^{n} x_{j}} \leq l_{i}, i=m+1, \ldots, m+d, \\
\sum_{j=1}^{n} x_{j} \leq h,
\end{gathered}
$$

$$
x_{j} \geq 0, j=1, \ldots, n,
$$

where Equation [4] is the objective function for which $z_{1}$ is the value representing dietary costs $(\$ /$ cow $\cdot d)$ for the first linear programming model, $c_{j}$ is the cost of feed $j(\$ / \mathrm{kg}$ of $\mathrm{DM}), x_{j}$ is the $j$ th decision variable representing the amount of feed $j(\mathrm{~kg}$ of DM), and $n$ is the number of feeds. Feeds available for diet formulations were from Castillo et al. (2013) and represent feeds used by 39 dairies surveyed in Merced County, California. Feed costs were collected locally in California and represent costs from February and March 2013 (Table 2 ). Equations [5] to [8] are constraint equations that determine the feasible region. In particular, Equation [5] sets the minimum nutrient requirement by using $a_{i j}$ as the content of nutrient $i$ on feed $j$ (MJ, g or $\mathrm{mg} /$ $\mathrm{kg}$ of $\mathrm{DM})$ and $b_{i}$ as the animal requirement of nutrient $i(\mathrm{MJ}, \mathrm{g}$ or $\mathrm{mg} / \mathrm{cow} \cdot \mathrm{d})$. Diets were formulated to sustain the milk production of the 39 dairies described by Castillo et al. (2013). Nutrient requirements of cows and nutrient composition of feeds were used according the NRC (2001) system as described in Moraes et al. (2012). However, the iterative procedure described by Moraes et al. (2012) for adjusting RDP, RUP, and $\mathrm{NE}_{\mathrm{L}}$ values and requirements was not used because of the relative robustness of the model solutions to changes in DMI. In particular, the feed-composition matrix and the vector of constraint right-hand sides were not iteratively updated as described by Moraes et al. (2012) to account for proportional changes in nutrient composition of feeds with deviations from the initial DMI. Equation [6] sets nutrient proportions and the inclusion of feeds to levels within predetermined intervals. In this notation, $\varphi_{i j}$ is the proportion of nutrient $i$ in feed $j$ $\left(\mathrm{kg} / \mathrm{kg}\right.$ of DM) and $u_{i}$ and $l_{i}$ are the lower and upper limits in kilograms per kilogram of DM. Specifically, dietary NDF $(\mathrm{kg} / \mathrm{kg}$ of $\mathrm{DM}$ ) was set between 0.3 and 0.4 , dietary $\mathrm{CP}(\mathrm{kg} / \mathrm{kg}$ of $\mathrm{DM})$ was set to be lower than 0.2 , dietary forage percentage $(\mathrm{kg} / \mathrm{kg}$ of $\mathrm{DM})$ was set to be between 0.35 and 0.65 , and dietary EE $(\mathrm{kg} /$ $\mathrm{kg}$ of DM) was set to be lower than 0.06. The inclu- 
Table 2. Dietary feed upper limits and feed costs

\begin{tabular}{llc}
\hline Feed & Limit $^{1}$ & Cost $^{2}$ \\
\hline Alfalfa silage & No limit & 0.30 \\
Alfalfa hay & No limit & 0.29 \\
Almond hulls & 0.10 & 0.20 \\
Bakery waste & 0.05 & 0.42 \\
Barley grain & No limit & 0.41 \\
Barley silage & No limit & 0.16 \\
Canola meal & 0.10 & 0.47 \\
Corn gluten feed & 0.05 & 0.36 \\
Corn grain-flaked & No limit & 0.43 \\
Corn silage & No limit & 0.21 \\
Whole cottonseed & No limit & 0.44 \\
Corn dried distillers grain & 0.10 & 0.39 \\
Grass silage & No limit & 0.13 \\
Molasses & 0.01 & 0.27 \\
Oats hay & No limit & 0.19 \\
Oats silage & No limit & 0.16 \\
Rice bran & 0.05 & 0.30 \\
Soybean meal & 0.10 & 0.58 \\
Sugar beet pulp & 0.10 & 0.36 \\
Tomatoes & 0.05 & 0.12 \\
Wheat hay & No limit & 0.25 \\
Wheat silage & No limit & 0.17 \\
Whey & 0.01 & 0.17 \\
Sodium bicarbonate & 0.005 & 0.34 \\
Sodium chloride & 0.005 & 0.14 \\
Mineral premix A & No limit & 1.05 \\
Mineral premix $\mathrm{B}^{4}$ & No limit & 0.76 \\
Mineral premix $\mathrm{C}^{5}$ & No limit & 7.15 \\
\hline In kilograms & &
\end{tabular}

${ }^{1}$ In kilograms per kilogram of diet DM.

${ }^{2}$ In dollars per kilogram of DM. Collected locally in California from February and March 2013.

${ }^{3}$ Contained $15 \% \mathrm{Ca}$ and $21 \% \mathrm{P}$.

${ }^{4}$ Contained $22.5 \% \mathrm{~S}, 18 \% \mathrm{~K}$, and $11.5 \% \mathrm{Mg}$.

${ }^{5}$ Contained $3.75 \% \mathrm{Zn}, 3 \% \mathrm{Mn}, 1.25 \% \mathrm{Cu}$, and $0.25 \%$ Co.

sion of determined feeds in the diet were also limited to predetermined proportions (Table 2) to ensure the formulation of realistic diets that would be readily accepted by dairy producers. Equation [7] was used to set the maximum DMI $h(\mathrm{~kg}$ of DM/cow.d) using the TMR intakes from Castillo et al. (2013).

Minimum Methane Model. The minimum $\mathrm{CH}_{4}$ model was formulated to minimize $\mathrm{CH}_{4}$ emissions while delivering nutrients to sustain a given level of milk production. The model objective function and constraints are described as follows:

$$
\min z_{2}=\beta_{0}+\beta_{1} \sum_{j=1}^{n} \phi_{1, j} x_{j}+\cdots+\beta_{p-1} \sum_{j=1}^{n} \phi_{p-1, j} x_{j},
$$

subject to

$$
\boldsymbol{x} \in F,
$$

where Equation [9] is the objective function for which $z_{2}$ is the value $(\mathrm{MJ} / \mathrm{cow} \cdot \mathrm{d})$ representing daily $\mathrm{CH}_{4}$ emis- sions for the second linear programming model, $\left\{\beta_{k}\right\}_{k=0}^{p-1}$ are the fixed regression coefficients from Equation [1], $\left\{\phi_{k, j}\right\}_{k=1}^{p-1}$ are the fractions of nutrients (for the independent variables in Equation [1]) of feed $j(\mathrm{~kg} / \mathrm{kg}$ of DM), and $x_{j}$ is the amount of feed $j(\mathrm{~kg}$ of DM). Equation [10] is used to state that the constraints of this linear programming model are the same ones used in the least cost diet model that specify a feasible region $F$ constrained by Equations [5] to [8].

\section{Goal Programming Model}

In the third part of the study, a goal programming model (Romero and Rehman, 1989) was developed to simultaneously minimize diet costs and $\mathrm{CH}_{4}$ emissions. In the goal programming framework, deviations from target values of each goal are minimized in a composite objective function. In this study, $\mathrm{CH}_{4}$ emissions and diet costs deviations from the optimal values of the objective functions of the 2 linear programming models were minimized. Similar to the linear programming models, the goal programming model was formulated to deliver nutrients to sustain the milk-production levels from Castillo et al. (2013), and daily nutrient requirements of animals and nutrient composition of feeds were calculated according the NRC (2001) guidelines. A weighted goal programming framework was used for which various levels of trade-off were determined by the systematic variation of the objective function weights. The model structure is described as follows:

$$
\min z_{3}=\sum_{q=1}^{2} w_{q}\left(\frac{n_{q}+p_{q}}{t_{q}}\right),
$$

subject to

$$
\begin{gathered}
\sum_{j=1}^{n} c_{j} x_{j}+n_{1}-p_{1}=t_{1}, \\
\beta_{0}+\beta_{1} \sum_{j=1}^{n} \phi_{1, j} x_{j}+\cdots+\beta_{p-1} \sum_{j=1}^{n} \phi_{p-1, j} x_{j}+n_{2}-p_{2}=t_{2}, \\
x \in F
\end{gathered}
$$

where $z_{3}$ is the goal programming objective function value for the third model, $w_{q}$ is the weight of the $q$ th goal (goal one is to minimize diet cost and goal 2 is to minimize $\mathrm{CH}_{4}$ emissions), $n_{q}$ and $p_{q}$ are the negative 
and positive deviation variables for goal $q\left(n_{j}\right.$ and $p$ $\geq 0$ ), $t_{q}$ is the target value for goal $q$, and Equations [12] and [13] are the goal constraints. The technical constraints specifying the feasible region $F$ are same as before (Equations [5]-[8]). It is important to note that this model specification naturally accommodates the goal programming restriction $n_{q} p_{q}=0, q=1,2$. The individual linear programming models' optimal values (Equations [4] and [9]) were used to set up the targets, that is $t_{1}=z_{1}$ and $t_{2}=z_{2}$. Furthermore, to identify the set of feasible solutions of the goal programming model, the exploration of the feasible set was conducted by the construction of a grid of weights for which $\sum_{q=1}^{2} w_{q}=1$, as suggested by Jones and Tamiz (2010). For instance, a factorial experiment was created with $w_{1}$ and $w_{2}$ varying from $(1,0)$ to $(0,1)$ in increments of 0.001 . At each one of the 1001 loci, the goal programing model was solved and solutions used for the construction of the solution set. In this weight grid specification, when $w_{1}$ $=0$, all the weight is placed in minimizing $\mathrm{CH}_{4}$ emissions and the goal programming model reduces to the minimum $\mathrm{CH}_{4}$ model (Equation [9]). On the other hand, when $w_{2}=0$, all the weight is placed in minimizing dietary costs and the goal programming model reduces to the least cost diet model (Equation [4]). At the intermediate weight grid loci, a trade-off is imposed with the different weights on minimizing diet costs versus minimizing $\mathrm{CH}_{4}$ emissions. The goal programming model was solved in the lpSolve package of the software R (Buttrey, 2005).

Sensitivity analysis plays an essential role in the interpretation of results in operations research. For instance, shadow prices represent the change in the objective function value by perturbing the right-hand side of a constraint by one unit (Winston and Venkataramanan, 2002). From an economic perspective, it represents the marginal value associated with an additional unit of a scarce resource. Moraes et al. (2012) used shadow prices to determine the price dairy producers would be willing to pay on carbon equivalent units in a potential carbon credit market. These determined marginal values were used to impute a trading value for residual emissions and calculate the marginal cost of $\mathrm{CH}_{4}$ emission mitigation (Moraes et al., 2012). Dairy producers could then decide between implementing regulatory policies on site and purchasing credits in a carbon credit market. In this study, we propose an alternative methodology to calculate the cost of $\mathrm{CH}_{4}$ mitigation through dietary manipulation that is directly determined by the goal programming model. We define the $\mathrm{CH}_{4}$-emission mitigation cost $(\mathrm{MC})$ as

$$
\mathrm{MC}(\$ / \mathrm{MJ})=\frac{\Delta \operatorname{Cost}(\$ / \mathrm{d})}{\Delta \mathrm{CH}_{4}(\mathrm{MJ} / \mathrm{d})},
$$

where $\Delta$ Cost $=$ Diet Cost ${ }_{s}-$ Diet Cost $_{s-1}$ and $\Delta \mathrm{CH}_{4}=$ $\mathrm{CH}_{4, s}-\mathrm{CH}_{4, s-1}$ for the sth distinct solution of the solution set generated by the goal programming model. The interpretation of the MC generated by Equation [14] is similar to the shadow prices determined by Moraes et al. (2012): the increase in dietary costs associated with a unit mitigation of $\mathrm{CH}_{4}$ emissions.

\section{RESULTS}

\section{Prediction of Methane Emissions}

The best model (smallest deviance information criterion) fitted to predict $\mathrm{CH}_{4}$ emissions used NDF and $\mathrm{CP}$ intakes as independent variables:

$$
\begin{gathered}
\mathrm{CH}_{4}=4.59(0.68)+1.46(0.16) \times \mathrm{NDF} \\
+1.39(0.31) \times \mathrm{CP}
\end{gathered}
$$

where $\mathrm{CH}_{4}$ is the methane emission $(\mathrm{MJ} / \mathrm{cow} \cdot \mathrm{d})$, NDF is the NDF intake $(\mathrm{kg}$ of $\mathrm{DM} / \mathrm{cow} \cdot \mathrm{d})$, and $\mathrm{CP}$ is the $\mathrm{CP}$ intake $(\mathrm{kg}$ of $\mathrm{DM} / \mathrm{cow} \cdot \mathrm{d})$. The model RMSE was $3.12 \mathrm{MJ} / \mathrm{d}$ or $19.4 \%$ of the mean observed $\mathrm{CH}_{4}$ emission $(16.6 \mathrm{MJ} / \mathrm{cow} \cdot \mathrm{d})$, suggesting a good ability of the selected model in describing the data. It is important to note that nutrient intakes were used as independent variables so the prediction equation could be directly used in the linear and goal programming models. Furthermore, the condition number of the design matrix (largest condition index) was 8.89, suggesting that multicollinearity was not an issue in this prediction equation (Belsley et al., 1980), and diagnostics plots (Figure 1) suggest good ability of the model in describing the data.

\section{Linear Programming Models}

The 2 linear programming models generated, as expected, distinct solutions. Diet costs, $\mathrm{CH}_{4}$ emissions, and nutrient composition of the solutions from the 2 models are in Table 3 . The least cost diet model generated a cheaper diet that resulted in more $\mathrm{CH}_{4}$ emitted than the diet formulated by the minimum $\mathrm{CH}_{4}$ model. The diet formulated by the least cost diet model cost $\$ 5.95 / \mathrm{cow} \cdot \mathrm{d}$ and generated a predicted $\mathrm{CH}_{4}$ emission of $21.6 \mathrm{MJ} / \mathrm{cow} \cdot \mathrm{d}$. The minimum $\mathrm{CH}_{4}$ model formulated a diet at a cost of $\$ 7.31 / \mathrm{cow} \cdot \mathrm{d}$ and generated a predicted $\mathrm{CH}_{4}$ emission of $17.9 \mathrm{MJ} / \mathrm{cow} \cdot \mathrm{d}$. The reduction in $\mathrm{CH}_{4}$ 
a)

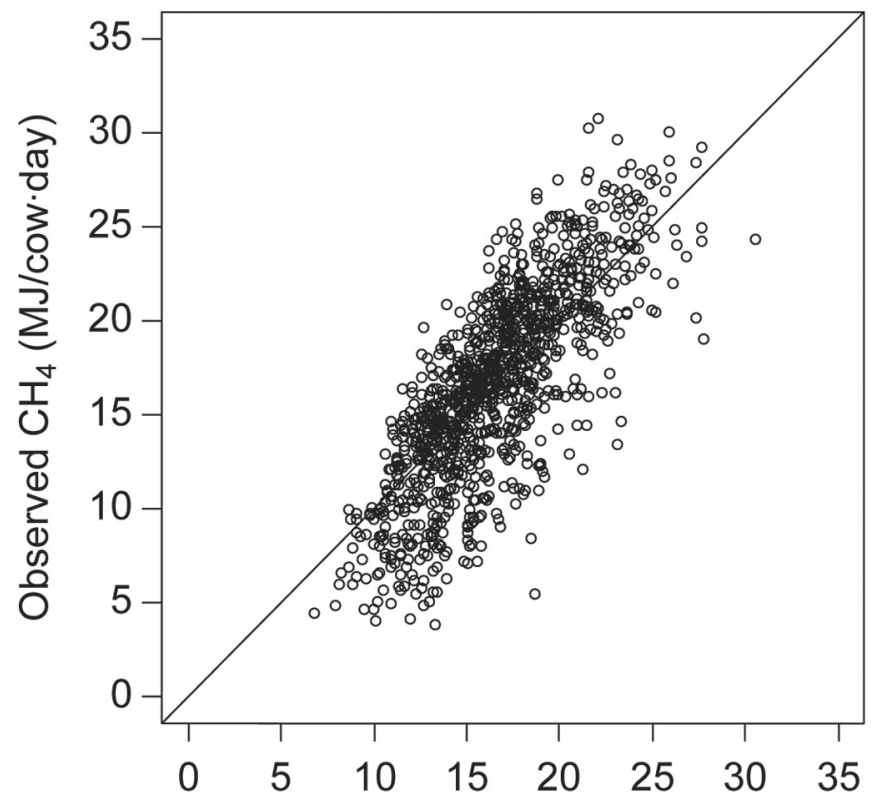

b)

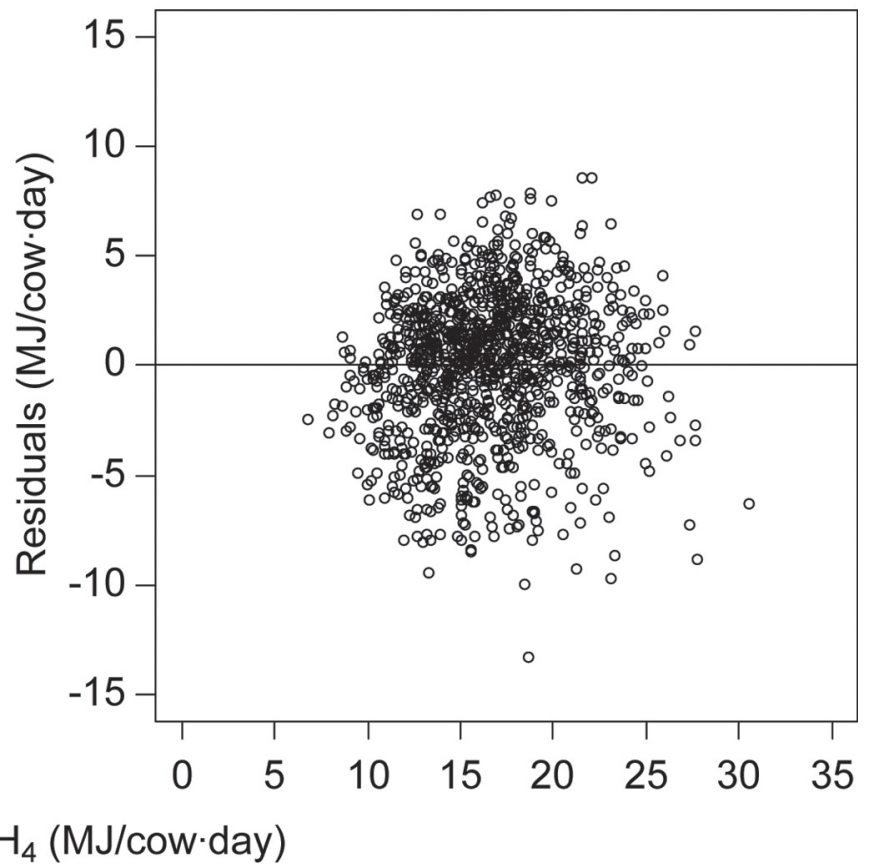

Figure 1. Diagnostic plots of the methane prediction model. Graph (a) shows observed versus predicted values with a line that has zero intercept and slope equal to one. Graph (b) shows residuals versus predicted values. Predicted $\mathrm{CH}_{4}$ emissions were calculated using only the fixed effects, i.e., $\hat{\mathbf{y}}=\mathbf{X} \hat{\boldsymbol{\beta}}$. Similarly, residuals were calculated using only the fixed effects, i.e., $\mathbf{e}=\mathbf{y}-\mathbf{X} \hat{\boldsymbol{\beta}}$. In this notation, $\hat{\mathbf{y}}$ are the predicted values, $\hat{\boldsymbol{\beta}}$ are the estimated regression coefficients, $\mathbf{y}$ are the observed methane emissions, and $\mathbf{e}$ are the residuals.

emissions was obtained by the manipulation of the nutrient composition of the diet and also by a reduction in DMI for the same level of milk production. In particular, dietary NDF was reduced to the minimum proportion set by the model constraints $(0.30 \mathrm{~kg} / \mathrm{kg}$ of DM) in the minimum $\mathrm{CH}_{4}$ model. Similarly, when comparing the least cost with the minimum $\mathrm{CH}_{4}$ model, the $\mathrm{CP}$ content of the diet increased from 0.181 to $0.198(\mathrm{~kg} / \mathrm{kg}$ of DM) and the EE content of the diet increased from 0.056 to $0.060(\mathrm{~kg} / \mathrm{kg}$ of $\mathrm{DM})$, which was the maximum set by the model constraint. Likewise, the $\mathrm{NE}_{\mathrm{L}}$ content of the diet increased from 6.63 to $7.22 \mathrm{MJ} / \mathrm{kg}$ of $\mathrm{DM}$ when comparing the least cost and the minimum $\mathrm{CH}_{4}$ models. The DMI decreased from 20.3 to $18.7 \mathrm{~kg}$ of $\mathrm{DM} /$ cow.d for the least cost and the minimum $\mathrm{CH}_{4}$ models, respectively. Nutrient composition differences in the 2 models were a result of the selection of different feeds and proportions of these feeds comprising the formulated diets. In the least cost diet model, oats and corn silages were the main forage sources, but in the minimum $\mathrm{CH}_{4}$ model, oats silage was replaced by alfalfa silage. The replacement of oats silage by alfalfa silage occurred because of the often-lower proportion of NDF in alfalfa silage than in oats silage. Similarly, the major diets' concentrate fractions were also altered when comparing the least cost and minimum $\mathrm{CH}_{4}$ mod- els. The model reduced the selection of feeds rich in NDF and increased the use of feeds rich in energy and protein, causing a reduction in $\mathrm{CH}_{4}$ achieved by a lower level of DMI.

\section{Goal Programming Model}

The weighting scheme of the goal programming model generated a solution set with 12 distinct solutions. Each solution represents a diet with distinct cost and predicted $\mathrm{CH}_{4}$ emission (Table 4, Figure 2). It is important to note that only 12 solutions were distinct because incremental changes of weights were often not

Table 3. Dietary nutrient composition, diet costs and methane emissions from the least cost and minimum methane linear programming models

\begin{tabular}{lcc}
\hline Item $^{1}$ & $\begin{array}{c}\text { Least cost } \\
\text { model }\end{array}$ & $\begin{array}{c}\text { Minimum } \\
\mathrm{CH}_{4} \text { model }\end{array}$ \\
\hline Diet cost $(\$ /$ cow $\cdot d)$ & 5.95 & 7.31 \\
$\mathrm{CH}_{4}(\mathrm{MJ} / \mathrm{cow} \cdot \mathrm{d})$ & 21.58 & 17.91 \\
$\mathrm{DMI}(\mathrm{kg} / \mathrm{cow} \cdot \mathrm{d})$ & 20.32 & 18.66 \\
Diet NDF $(\%$ of $\mathrm{DM})$ & 40.00 & 30.00 \\
Diet ether extract $(\%$ of DM) & 5.62 & 6.00 \\
Diet $\mathrm{CP}(\%$ of DM) & 18.10 & 19.78 \\
Diet $\mathrm{NE}$ (MJ/kg of $\mathrm{DM})$ & 6.63 & 7.22 \\
\hline
\end{tabular}

${ }^{1} \mathrm{CH}_{4}=$ methane emission. 
large enough to cause a change in basis from the previous solution (i.e., the solution moving to another vertex of the simplex). Figure 3 shows the changes in the solutions with incremental changes in the weights. The 2 curves represent deviations of the goal programming solution from the target level: $p_{1}(\$ / \mathrm{cow} \cdot \mathrm{d})$ represents the deviation in dietary costs from its target and $p_{2}$ $(\mathrm{MJ} / \mathrm{cow} \cdot \mathrm{d})$ represents the deviation in $\mathrm{CH}_{4}$ emission from its target. The $x$-axis is the locus of the weight grid starting with objective function weights of $(1,0)$ for locus 1 , where all weight was placed in minimizing diet cost, until $(0,1)$ for locus 1001 , where all weight was placed in minimizing emissions. The segments of the curves that have zero slope represent changes in weights for which a change in solution basis did not occur. Conversely, the jump points in the curves represent weights for which a new solution is identified, representing the formulation of a new diet with new cost and predicted $\mathrm{CH}_{4}$ emissions. Furthermore, the range in weights (Table 4) that determined a given $\mathrm{CH}_{4}$ emission and diet cost, or similarly the length of the curve segments (Figure 3) with no jump points, can be used to assess the sensitivity of a specific diet to an intensity level of $\mathrm{CH}_{4}$ mitigation. For instance, if the range of weights for a given level of $\mathrm{CH}_{4}$ emission and diet cost is large, that solution level is relatively insensitive to small changes in the desired trade-off. Conversely, if solutions are more sensitive to changes in the weighting, the range of weights for a given level of $\mathrm{CH}_{4}$ and costs will be narrow. Similarly, the graphical representation of the stability of solutions presented in Figure 3 has $p_{1}$ and $p_{2}$ plotted versus the weight grid locus. The proportional decrease in $w_{1}$ (decreasing the weight of minimizing diet cost) caused the increase in

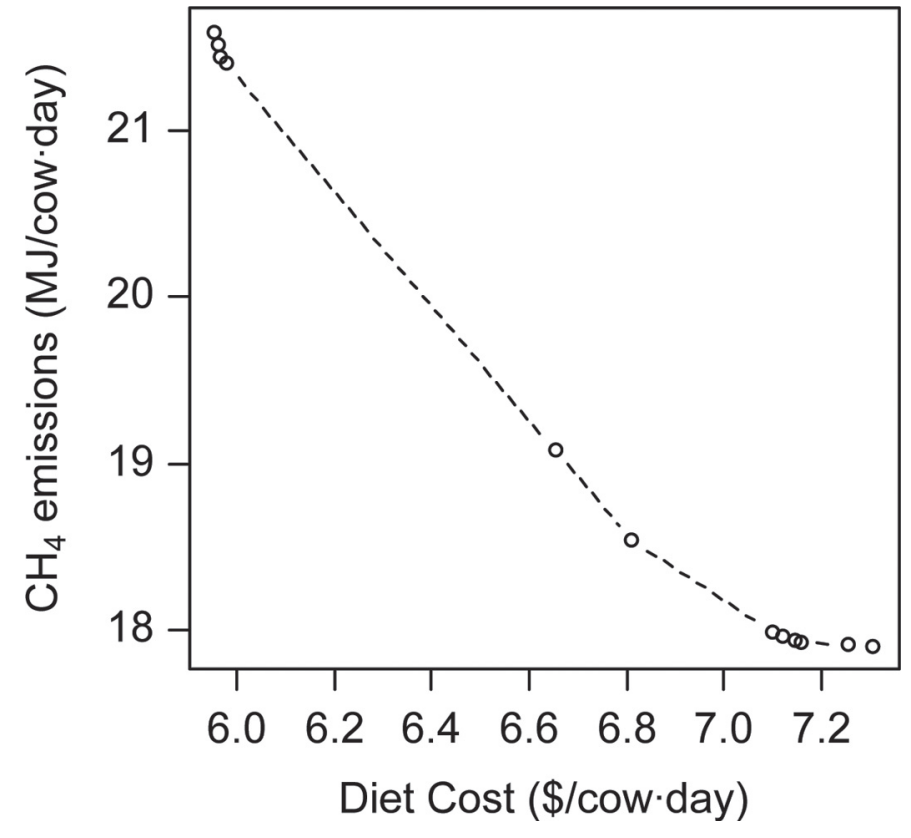

Figure 2. Methane emissions versus diet costs from the solutions of the weighted goal programming model on a per cow daily basis.

$p_{1}$, leading to an increase in dietary costs and decrease in $\mathrm{CH}_{4}$ emissions. Likewise, the sequential increase in $w_{2}$ (increasing the weight of minimizing $\mathrm{CH}_{4}$ ) also leads to formulation of more expensive diets and reduced $\mathrm{CH}_{4}$ emissions.

The set of feasible solutions (Table 4) enables the selection of diets with a desired level of trade-off between increase in dietary costs and reduction in $\mathrm{CH}_{4}$ emissions. For example, in the first row of Table 4, dietary costs are at their minimum set by the target

Table 4. Goal programming ranges of weights, diet costs, and methane emissions for the 12 goal programming distinct solutions ${ }^{1}$

\begin{tabular}{lllcccc}
\hline $\begin{array}{l}\text { Unique } \\
\text { solution }\end{array}$ & \multicolumn{1}{c}{$w_{1}$} & \multicolumn{1}{c}{$w_{2}$} & $\begin{array}{c}\text { Diet cost } \\
(\$ / \text { cow } \cdot d)\end{array}$ & $\begin{array}{c}\Delta \text { Diet } \\
\text { cost }(\%)\end{array}$ & $\begin{array}{c}\text { Methane } \\
(\mathrm{MJ} / \text { cow } \cdot \mathrm{d})\end{array}$ & $\begin{array}{c}\Delta \text { Methane } \\
(\%)\end{array}$ \\
\hline 1 & $1-0.876$ & $0-0.124$ & 5.95 & - & 21.58 & 20.54 \\
2 & $0.875-0.819$ & $0.125-0.181$ & 5.96 & 0.08 & 21.51 & 20.11 \\
3 & $0.818-0.613$ & $0.182-0.387$ & 5.97 & 0.19 & 21.44 & 19.75 \\
4 & $0.612-0.606$ & $0.388-0.394$ & 5.98 & 0.41 & 21.39 & 19.49 \\
5 & $0.605-0.604$ & $0.395-0.396$ & 6.65 & 11.73 & 19.08 & 6.56 \\
6 & $0.603-0.463$ & $0.397-0.537$ & 6.81 & 14.39 & 18.54 & 3.54 \\
7 & $0.462-0.331$ & $0.538-0.669$ & 7.09 & 19.24 & 17.98 & 0.44 \\
8 & $0.330-0.303$ & $0.670-0.697$ & 7.12 & 19.59 & 17.96 & 0.31 \\
9 & $0.302-0.248$ & $0.698-0.752$ & 7.15 & 20.01 & 17.94 & 0.17 \\
10 & $0.247-0.080$ & $0.753-0.920$ & 7.16 & 20.19 & 17.93 & 0.13 \\
11 & $0.079-0.038$ & $0.921-0.962$ & 7.25 & 21.83 & 17.91 & 0.02 \\
12 & $0.037-0$ & $0.963-1$ & 7.31 & 22.70 & 17.91 & - \\
\hline
\end{tabular}

${ }^{1}$ Unique solution is the identification of the unique solution in the set of feasible solutions, $w_{1}$ and $w_{2}$ are the ranges of goal programming weights that determined the same solution, Diet cost $(\$ /$ cow $\cdot d)$ is the diet cost on a cow basis, $\Delta$ Diet cost $(\%)$ is the proportional increase in diet cost from the target diet cost $\left(t_{1}=\$ 5.95 /\right.$ cow.d), Methane (MJ/cow·d) is the methane emission on a cow basis, and $\Delta$ Methane (\%) is the proportional increase in methane emissions from the target emission $\left(t_{2}=17.91 \mathrm{MJ} / \mathrm{cow} \cdot \mathrm{d}\right)$. 


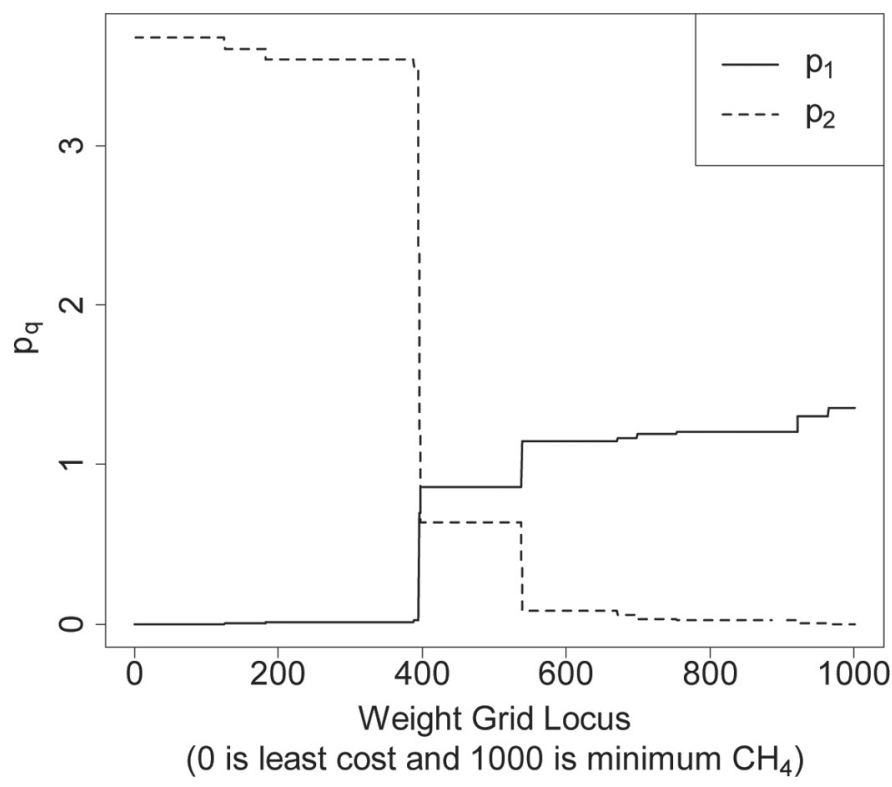

Figure 3. Deviational variables of the weighted goal programming model versus the weight grid locus representing the deviations of each solution point to the target levels set by the individual linear programming models. $p_{q}$ denotes the positive deviational variable from the qth goal (minimize dietary cost or minimize methane emissions). Such variables represent deviations from the goal programming solution to the target level: $p_{1}(\$ /$ cow $\cdot \mathrm{d})$ represents the deviation in dietary costs from its target; $p_{2}(\mathrm{MJ} / \mathrm{cow} \cdot \mathrm{d})$ represents the deviations from the target methane emission. The $x$-axis is the locus of the weight grid starting with objective function weights of $(1,0)$ for locus 1 , where all weight is placed in minimizing diet cost, until $(0,1)$ for locus 1001 , where all weight is placed in minimizing emissions. Sequential increments in weight are of 0.001 .

level $\$ 5.95 / \mathrm{cow} \cdot \mathrm{d}$ and $\mathrm{CH}_{4}$ emissions are $3.67 \mathrm{MJ} / \mathrm{cow} \cdot \mathrm{d}$ above its target level $\left(\mathrm{CH}_{4}=3.67+17.9=21.6 \mathrm{MJ} /\right.$ cow.d). Conversely, in the last row, $\mathrm{CH}_{4}$ emissions are at their minimum level of $17.9 \mathrm{MJ} / \mathrm{cow} \cdot \mathrm{d}$ and dietary costs are $\$ 1.36 / \mathrm{cow} \cdot \mathrm{d}$ above its target level [Cost $=1.36$ $+5.95=\$ 7.31 / \mathrm{cow} \cdot \mathrm{d}]$. The 10 middle solutions represent compromised solutions, which may be selected by the decision maker according to the trade-off limits. Overtly, solutions at the upper part of the table have more weight on minimizing dietary costs, and solutions at the lower part of the table have more weight on emission minimization. For example, at row 5 (Table 4 ), dietary costs are $\$ 6.65 / \mathrm{cow} \cdot \mathrm{d}$ and $\mathrm{CH}_{4}$ emissions are 19.1 MJ/cow.d, and at row 9 (Table 4), dietary costs are $\$ 7.15 / \mathrm{cow} \cdot \mathrm{d}$ and $\mathrm{CH}_{4}$ emissions are $17.9 \mathrm{MJ} / \mathrm{cow} \cdot \mathrm{d}$. The changes in $\mathrm{CH}_{4}$ emissions and dietary costs were a result of formulation of different diets that supply daily nutrient requirements for the dairies from Castillo et al. (2013). For each of the 12 diets, the delivery of nutrients is greater or equal to the requirements of animals set by the NRC (2001) model and can be achieved at different combinations of DMI and diet nutrient density.
For instance, $\mathrm{DMI} ; \mathrm{NE}_{\mathrm{L}}$ intake; and dietary contents of NDF, CP, and EE are plotted against the weight grid locus in Figure 4. When $w_{1}$ decreased and $w_{2}$ increased (weight grid locus went from 1 to 1001), more weight was placed in reducing $\mathrm{CH}_{4}$ emissions rather than minimizing dietary costs. Therefore, DMI was reduced because it is a major determinant of enteric $\mathrm{CH}_{4}$ emissions and dietary $\mathrm{NE}_{\mathrm{L}}$ and $\mathrm{CP}$ contents increased to meet the nutrient requirement of an animal at a lower DMI level.

Mineral and nitrogen excretions and $\mathrm{CH}_{4}$, ammonia, and nitrous oxide emissions are potential environmental impacts generated in the process of milk production. The goal programming model structure directly provides potential nutrient excretions calculated by mass balance (i.e., delivered - required). Figure 5 presents surpluses (i.e., amounts fed above maintenance) of phosphorus, potassium, chlorine, sodium, RDP, and RUP. Both protein forms were fed at the requirement level for all the weight combinations of the goal programming model. It is important to notice that this does not imply a zero nitrogen balance because surpluses were not calculated on a nitrogen basis. The 4 minerals examined were fed at different levels above maintenance for the various goal programming weights, suggesting that the amount of these minerals fed above maintenance, and potentially excreted to the environment, would change with different levels of $\mathrm{CH}_{4}$ mitigation. Furthermore, the goal programming model also provided a strategy for examining $\mathrm{CH}_{4}$ emission mitigation costs. The mitigation costs (Table 5) increased monotonically with the increase in the intensity of $\mathrm{CH}_{4}$ mitigation and ranged from $\$ 0.064$ to $\$ 11.6 / \mathrm{MJ}$ of $\mathrm{CH}_{4}$. The global warming potential of $\mathrm{CH}_{4}$ can be used to convert mitigation costs to dollars per unit of carbon dioxide equivalent $\left(\mathbf{C O}_{2}-\mathbf{e}\right)$. The 28 global warming potential of $\mathrm{CH}_{4}$ gas represents the proportional potential of $\mathrm{CH}_{4}$ in contributing to global warming over a 100-yr horizon in relation to carbon dioxide (IPCC, 2013). In this context, mitigation costs expressed per unit of $\mathrm{CO}_{2}$-e ranged from $\$ 127$ to $\$ 23,119 / \mathrm{t}$ of $\mathrm{CO}_{2}$-e [i.e., $\$ 0.064 / \mathrm{MJ}$ of $\mathrm{CH}_{4} \times 55,650 \mathrm{MJ} / \mathrm{t}$ of $\mathrm{CH}_{4} \times 1 / 28$ $\mathrm{t}$ of $\mathrm{CH}_{4} / \mathrm{t}$ of $\mathrm{CO}_{2}-\mathrm{e}=\$ 127 / \mathrm{t}$ of $\left.\mathrm{CO}_{2}-\mathrm{e}\right]$.

\section{DISCUSSION}

\section{Prediction of Methane Emissions}

The prediction model developed in this study had a particular structure dictated by its use in the linear and goal programming models. In particular, proportionality and additivity assumptions are key in linear programming models (Winston and Venkataramanan, 

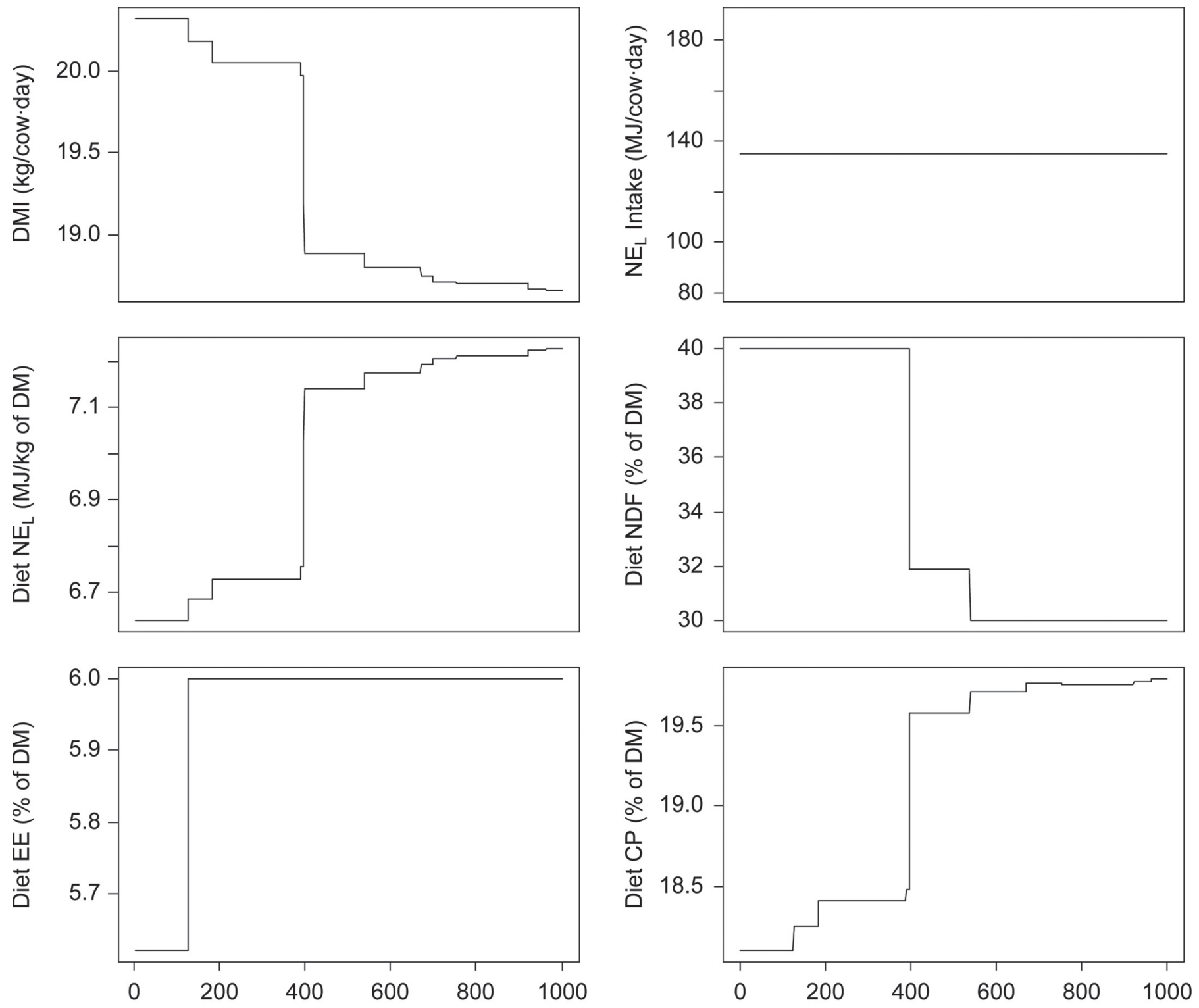

Weight Grid Locus ( 0 is least cost and 1000 is minimum $\mathrm{CH}_{4}$ )

Figure 4. Dry matter intake, $\mathrm{NE}_{\mathrm{L}}$ intake, and diet composition versus the goal programming weight grid locus, representing the changes in these variables for each goal programming solution. $\mathrm{NDF}=\mathrm{NDF}$ diet percentage, $\mathrm{EE}=$ ether extract diet percentage, and $\mathrm{CP}=\mathrm{CP}$ diet percentage. The $x$-axis is the locus of the weight grid starting with objective function weights of $(1,0)$ at locus 1 , where all weight is placed in minimizing diet cost, until $(0,1)$ at locus 1001 , where all weight is placed in minimizing emissions, with sequential 0.001 increments.

2002). The use of nutrient intakes as independent variables ensured that these assumptions were satisfied and respected the mass balance approach of the linear optimization models. The underlying strategy behind the model-selection procedure in this study was to identify, from the set of models predicting $\mathrm{CH}_{4}$ emissions with nutrient intakes, the model that minimized the deviance information criterion and had a design matrix condition number smaller than 10. However, it is important to point out that the biological interpretation of regression coefficients is limited when compared with more mechanistic models in which parameters often have a clear biological meaning. Furthermore, the main objective of this study was to develop a general framework for jointly minimizing environmental impacts of livestock production and diet costs and not to explain the underlying biological principles behind prediction of methane emissions with linear models. The model to predict $\mathrm{CH}_{4}$ emissions is a small part of the linear and goal programming models and may be easily replaced 

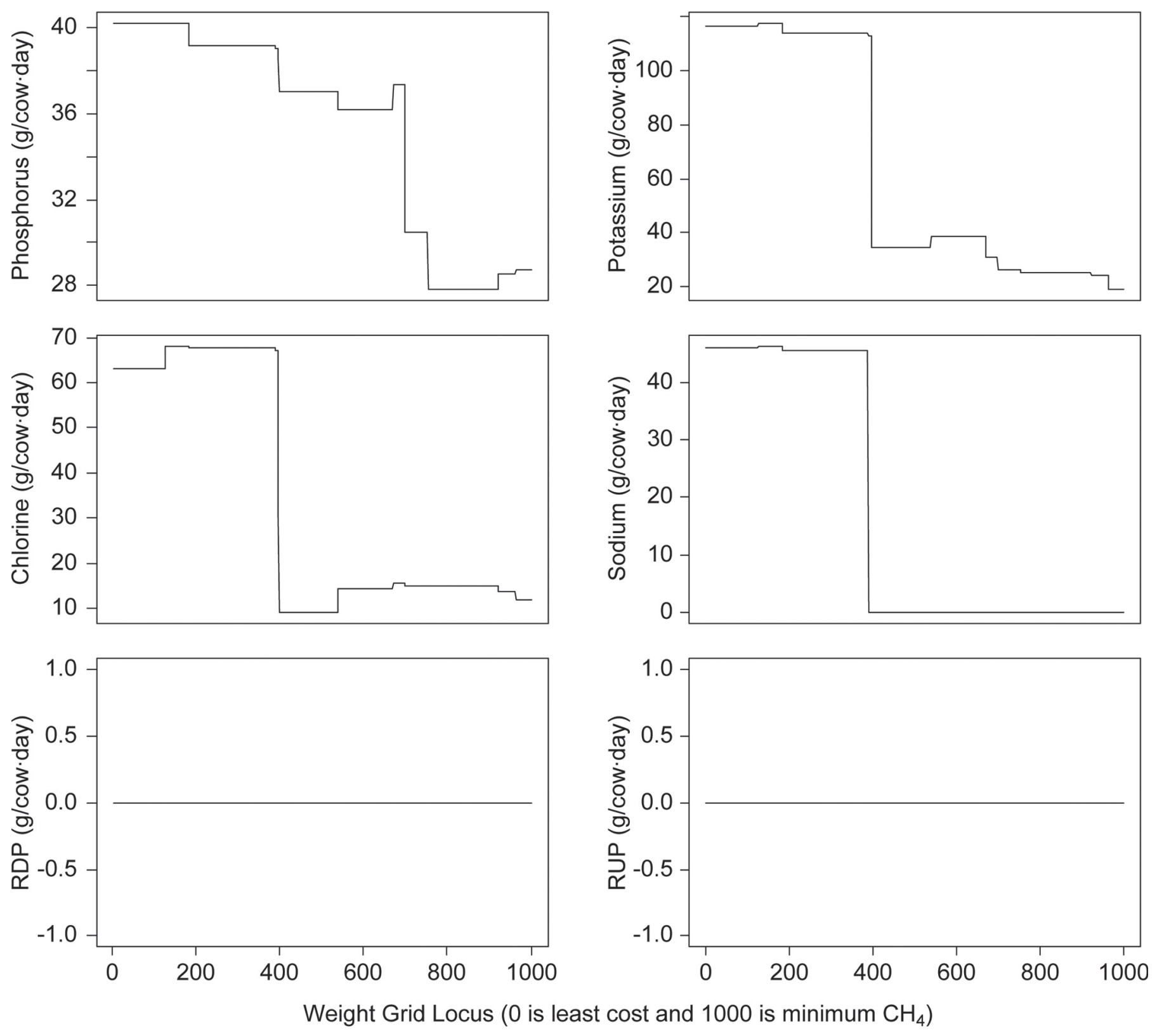

Figure 5. Surplus nutrient fractions in the diets formulated by the goal programming model. Values represent the amount fed above maintenance and were calculated by supplied minus required. These can be used to investigate potential mineral and nitrogen excretions. The $x$-axis is the locus of the weight grid starting with objective function weights of $(1,0)$ at locus 1 , where all weight is placed in minimizing diet cost, until $(0,1)$ at locus 1001 , where all weight is placed in minimizing emissions, with sequential 0.001 increments.

with another linear prediction equation of similar structure. Recently, Moraes et al. (2014) developed $\mathrm{CH}_{4}$ prediction models using robust model selection and fitting techniques and investigated independent variables that were key in predicting emissions comprehensively. These fitted equations were based on biological and statistical principles primarily focused on the prediction of $\mathrm{CH}_{4}$ emissions from different classes of cattle and were evaluated with independent data in a cross-validation procedure. In this context, we suggest the use of the prediction models from Moraes et al. (2014) when the main objective is predicting $\mathrm{CH}_{4}$ emissions rather than the use of predicted $\mathrm{CH}_{4}$ emissions within a linear programming framework. Nevertheless, the evaluation of the $\mathrm{CH}_{4}$ prediction models from this study suggests good ability of the model in describing the observed data. In particular, observed versus predicted plots (Figure 1) show no severe mean or slope bias in the fitted model because observations were mostly uniformly distributed along the unit line and the plot does not 
Table 5. Methane-emission mitigation costs (MC) for the 12 distinct goal programming solutions ${ }^{1}$

\begin{tabular}{lccc}
\hline \multicolumn{1}{l}{ Solution } & $\begin{array}{c}\mathrm{MC} \\
(\$ / \mathrm{MJ})\end{array}$ & $\begin{array}{c}\mathrm{MC} \\
\left(\$ / \mathrm{kg} \text { of } \mathrm{CH}_{4}\right)\end{array}$ & $\begin{array}{c}\mathrm{MC} \\
\left(\$ / \mathrm{t} \text { of } \mathrm{CO}_{2}-\mathrm{e}\right)\end{array}$ \\
\hline $2-1$ & 0.06 & 3.54 & 126.67 \\
$3-2$ & 0.09 & 5.50 & 196.59 \\
$4-3$ & 0.28 & 15.75 & 562.66 \\
$5-4$ & 0.29 & 16.19 & 578.21 \\
$6-5$ & 0.29 & 16.34 & 583.50 \\
$7-6$ & 0.52 & 28.90 & 1,032 \\
$8-7$ & 0.91 & 50.42 & 1,800 \\
$9-8$ & 1.03 & 57.26 & 2,045 \\
$10-9$ & 1.36 & 75.65 & 2,701 \\
$11-10$ & 5.19 & 289.34 & 10,333 \\
$12-11$ & 11.63 & 647.33 & 23,119 \\
\hline
\end{tabular}

${ }^{1} \Delta$ Solution is the identification of the 2 unique solutions used to calculate the mitigation costs at each row, and $\mathrm{MC}$ is the methane mitiga-

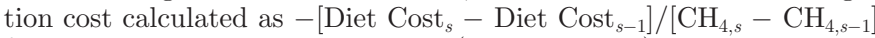
for the $s$ th unique solution point $(s=2, \ldots, 12)$. It was assumed that the energetic content of $\mathrm{CH}_{4}$ was $55.65 \mathrm{MJ} / \mathrm{kg}$. The $\mathrm{CO}_{2}$-e is the carbon dioxide equivalent of $\mathrm{CH}_{4}$, which was calculated by the mass of $\mathrm{CH}_{4}$ times its global warming potential, which is assumed to be 28 times the global warming potential of the $\mathrm{CO}_{2}$ (IPCC, 2013).

suggest a clear deviation from the zero intercept. The residual versus predicted values plot (Figure 1) suggests good ability of the model in describing the data because no clear systematic pattern is evident. Finally, the RMSE, used as an indicator of the distance between the observations and model predictions, suggests good ability of the model in fitting the data as indicated by the relatively small magnitude of the RMSE in relation to the average $\mathrm{CH}_{4}$ emission.

\section{Linear and Goal Programming Models}

The $\mathrm{CH}_{4}$ mitigation strategy underlying the linear and goal programming models was to identify diets that generate reduced amounts of $\mathrm{CH}_{4}$ while delivering the required nutrients for a given level of milk production. These diets were often more expensive than the least cost diets and had an altered nutrient composition. For example, dietary NDF content was decreased in diets that generated reduced amounts of $\mathrm{CH}_{4}$. The reduction of dietary NDF to minimize $\mathrm{CH}_{4}$ emissions is biologically sound because the role of structural carbohydrates in determining $\mathrm{CH}_{4}$ emissions is well established (Moe and Tyrrell, 1979; Moraes et al., 2014). For instance, the fermentation of structural carbohydrates in the rumen leads to the production of proportionally greater acetate (Murphy et al., 1982), which generates greater amount of hydrogen serving as substrate for methanogens (Van Soest, 1994). Therefore, decreased amounts of $\mathrm{CH}_{4}$ may be obtained through the reduction of dietary NDF to levels determined by the constraints of the programming models. It is important to note that reducing dietary fiber to levels lower than levels recom- mended by the NRC (2001) may compromise ruminal and cow health, affecting milk production. Furthermore, recent studies suggested that increasing dietary lipids contents and modifying the types of dietary lipids may effectively alter $\mathrm{CH}_{4}$ emissions from ruminants (Hook et al., 2010; Martin et al., 2010; Hristov et al., 2013; Patra, 2013). The increase in dietary EE was not directly forced by the model structure because the selected $\mathrm{CH}_{4}$ prediction equation did not use dietary $\mathrm{EE}$ as an independent variable. However, reductions in $\mathrm{CH}_{4}$ emissions were achieved through the reduction of nutrient intakes, therefore leading the model to select a diet that had a greater nutrient density. Specifically, dietary CP, $\mathrm{EE}$, and $\mathrm{NE}_{\mathrm{L}}$ contents were increased in diets aimed at reducing $\mathrm{CH}_{4}$ emissions (Figure 4). From a modeling perspective, the observed changes in diet composition in this study were consistent with results from Moraes et al. (2012), where a reduction in $\mathrm{CH}_{4}$ emissions was also achieved with the formulation of diets with a lower proportion of dietary fiber, higher contents of energy and protein, and a reduction in DMI.

The constraint specifying the intake of the animal (Equation [7]) sets the DMI to be less or equal than the TMR intakes from Castillo et al. (2013). In this context, the model is driven by the delivery of nutrients, which has to meet the animal nutrient requirements, rather than the formulation of a diet for a fixed DMI. Therefore, reductions in DMI are allowed in the model structure given that the delivery of nutrients still meets the animal nutrient requirements calculated by the NRC (2001). Reductions in DMI are sometimes associated with changes in feeding behavior and potential reductions in milk yields due to competition between animals. The linear and goal programming models from this study can be easily modified to formulate diets for a fixed DMI or to set the DMI to be within predetermined levels. Specifically, the less-than-or-equal-to sign from Equation [7] may be replaced by an equal sign, forcing the model structure to keep the DMI fixed while altering dietary nutrient concentrations to achieve the decrease in $\mathrm{CH}_{4}$ emissions. Nevertheless, it is interesting to note that the total delivery of $\mathrm{NE}_{\mathrm{L}}$ in the goal programming model was constant over different solutions and it was at the requirement level for every model solution. These results suggest that the proposed goal programming model, with the assumptions and technical coefficients described above, behaves similarly to a model that sets the $\mathrm{NE}_{\mathrm{L}}$ intake to a fixed level. Cows receiving the 12 different diets formulated by the goal programming model would therefore produce the same amount of milk.

Mitigation costs in this study were substantially high, corroborating with results from Moraes et al. (2012), who determined high costs of reducing substantial 
amounts of $\mathrm{CH}_{4}$ emissions using a different set of feeds, animals, and methodology. These costs represent the increase in dietary costs associated with a unit reduction of $\mathrm{CH}_{4}$ emissions and may be used to determine imputed trading value of residual $\mathrm{CH}_{4}$ emissions. Dairy producers can use mitigation costs when trading their emission units in policy designs such as the cap-andtrade systems. For example, if mitigation costs are higher than costs associated with carbon units in the carbontrading market, producers may purchase emission units and not implement regulations on site. Conversely, if mitigation costs are lower than costs associated with units from the emission-trading market, producers may implement regulatory policies on site with the possibility of trading their residual emissions. These results also suggest that if $\mathrm{CH}_{4}$ regulatory policies were implemented in the dairy industry and producers relied on dietary manipulation for $\mathrm{CH}_{4}$ mitigation, trading credits in the carbon market would be a gainful strategy. It is important to note that emissions costs are specific to our data set of lactating dairy cows and the adopted feed prices. Therefore, they should be interpreted with caution because extrapolation to other production systems may not be valid. Also, only emissions from enteric fermentation are considered in this study, and the potential changes in emissions at other stages of the production system are not considered. For example, the model does not account for emissions from manure and from secondary sources such as fertilizers used in the field. Likewise, the timeframe of the proposed model is one day as the daily nutrient requirements are the main drivers of the model solution. Consequently, the model does not represent changes in the herd structure over time. How changes in the conception and culling rates of animals would affect the trade-off among diet costs and methane emissions are therefore not represented in our model. However, the use of the proposed goal programming model within a herd structure dynamic model (e.g., Kristensen, 1992; Cabrera, 2010; Giordano et al., 2012) would allow the characterization of the effects of changing the proportions of each animal class within a dairy on the trade-offs between minimizing dietary costs and $\mathrm{CH}_{4}$ emissions.

Several studies have suggested a trade-off between mineral and nitrogen excretions with the reduction of $\mathrm{CH}_{4}$ emissions (Moraes et al., 2012; Dijkstra et al., 2013; Sauvant et al., 2014). Therefore, monitoring nitrogen and mineral excretion while examining $\mathrm{CH}_{4}$ mitigation is fundamental to ensure that a reduction in $\mathrm{CH}_{4}$ emissions does not increase other routes of environmental impacts. For instance, Moraes et al. (2012) reported that nitrogen and potassium excretions increased by 16.5 and $16.7 \%$ with a $13.5 \%$ reduction in $\mathrm{CH}_{4}$ emissions from a baseline least cost diet. Similarly, Dijkstra et al. (2011) suggested an average increase of $0.30 \mathrm{~g}$ of $\mathrm{CH}_{4}$ per gram of urinary $\mathrm{N}$ decrease using various nutritional strategies with grass silage-based diets. Delivering protein and minerals above the requirement level potentially increases nitrogen and mineral excretion to the environment. For instance, protein overfeeding may increase nitrate run-off to the environment, contributing to eutrophication, and manure ammonia volatilization may cause respiratory problems in humans and animals as discussed by Reed et al. (2014). At the same time, excess mineral consumption may alter electrolyte balance and negatively affect milk production and animal health. Therefore, maintaining mineral and protein delivery within predetermined levels is necessary not only to reduce environmental impacts of livestock production but also to avoid mineral toxicities. The goal programming model structure directly provides potential nutrient excretions calculated by mass balance (Figure 5). For instance, all the diets formulated by the proposed model have levels of major macrominerals below toxic levels as reported by the NRC (2001). Furthermore, the linear and goal programming model structures can be easily modified to accommodate additional limits on the levels of protein and mineral supply. Specifically, the dietary content of a certain mineral may be constrained to a maximum value with the use of Equation [6] where $l$ sets the mineral upper dietary limit.

Finally, the goal programming model structure is flexible and may be adapted to the joint minimization of diet costs and other potential environmental impacts (e.g., nitrogen excretion). It is also flexible in the sense that $\mathrm{CH}_{4}$ predictions, dietary costs, feed nutrient composition, and animal nutrient requirements can be easily altered to accommodate various production systems. Additionally, the linear and goal programming structures can be used along with dynamic herd structure models (e.g., Giordano et al., 2012) in which changes in herd structure may affect the dairy total nutrient requirement. Furthermore, mechanistic models (Baldwin, 1995) may be used to calculate the nutrient requirements and predict milk production for a given level of supplied nutrients. In this framework, the model would represent changes in milk production with the changes in the delivery of nutrients. Alternatively, the proposed optimization models can be easily incorporated into whole-farm models (Rotz et al., 2013) that represent farm-level nutrient balance. Most importantly, the model can be easily incorporated into freely available systems for management of individual farm data of producers. For example, the framework proposed in this study can be incorporated into the Farm Smart system (Tricarico and Osborne, 2014), which provides self-assessment of environmental footprint and 
uses a model integration environment (Tricarico and Osborne, 2014).

\section{CONCLUSIONS}

A weighted goal programming model was developed for the joint minimization of dietary costs and $\mathrm{CH}_{4}$ emissions according to the willingness to meet a specific goal (diet cost vs. $\mathrm{CH}_{4}$ emissions). This framework extended the linear programming model recently proposed by Moraes et al. (2012) because it generates a set of feasible solutions rather than a single solution. In practical terms, the model identifies a set of diets with different costs and predicted $\mathrm{CH}_{4}$ emissions that deliver a similar amount of nutrients. The decision maker can then choose from the set according to feeding costs, $\mathrm{CH}_{4}$ mitigation level, and system characteristics (e.g., availability of feeds). The model is based on a systematic weighting scheme of the objective function for the identification of the set of solutions with various tradeoff levels between the 2 goals. The model structure allows the calculation of $\mathrm{CH}_{4}$ mitigation costs, which can be used to determine a trading value of emissions. In this study, mitigation costs were substantially high, suggesting that mitigating $\mathrm{CH}_{4}$ by dietary manipulating may be expensive. The goal programming model structure is flexible so that $\mathrm{CH}_{4}$ predictions, feed prices, nutrient composition of feeds, and animal nutrient requirements can be easily modified. Furthermore, information about nitrogen and mineral excretions for different $\mathrm{CH}_{4}$-reduction levels are readily available in the model structure and are based on mass conservation laws. Therefore, the optimization framework developed can be applied to the examination and minimization of dietary costs and environmental impacts of various livestock production systems.

\section{ACKNOWLEDGMENTS}

The research was supported by the Innovation Center for US Dairy (Rosemont, IL) Cow of the Future program. The authors thank the anonymous reviewers for their valuable comments and suggestions.

\section{REFERENCES}

Baldwin, R. L. 1995. Modeling Ruminant Digestion and Metabolism. Chapman Hall, London, UK.

Belsley, D. A., E. Kuh, and R. E. Welsch. 1980. Regression Diagnostics: Identifying Influential Data and Sources of Collinearity. John Wiley Sons, New York, NY.

Blaxter, K. L. and J. L. Clapperton. 1965. Prediction of the amount of methane produced by ruminants. Br. J. Nutr. 19:511-521.

Boadi, D., C. Benchaar, J. Chiquette, and D. Massé. 2004. Mitigation strategies to reduce enteric methane emissions from dairy cows: Update review. Can. J. Anim. Sci. 84:319-335.
Buttrey, S. 2005. Calling the lp_solve Linear Program Software from R, S-Plus and Excel. J. Stat. Softw. 14:1-13.

Cabrera, V. 2010. A large Markovian linear program to optimize replacement policies and dairy herd net income for diets and nitrogen excretion. J. Dairy Sci. 93:394-406.

CARB. 2008. Appendix C, Cap and trade. Pages 11-24 in Climate Change Proposed Scoping Plan. California Air Resour. Board, Sacramento.

Castillo, A. R., N. R. St-Pierre, N. Silva del Rio, and W. P. Weiss 2013. Mineral concentrations in diets, water, and milk and their value in estimating on-farm excretion of manure minerals in lactating dairy cows. J. Dairy Sci. 96:3388-3398.

Dantzig, G. B. 1963. Linear Programming and Extensions. 2nd ed. Princeton Univ. Press, Princeton, New Jersey.

De Vries, A. 2006. Economic value of pregnancy in dairy cattle. J. Dairy Sci. 89:3876-3885.

Dijkstra, J., O. Oenema, and A. Bannink. 2011. Dietary strategies to reducing $\mathrm{N}$ excretion from cattle: Implications for methane emissions. Curr. Opin. Environ. Sustain. 3:414-422.

Dijkstra, J., C. K. Reynolds, E. Kebreab, A. Bannink, J. L. Ellis, J. France, and A. M. van Vuuren. 2013. Challenges in ruminant nutrition: Towards minimal nitrogen losses in cattle. Pages $47-58$ in Energy and Protein Metabolism and Nutrition in Sustainable Animal Production. J. W. Oltjen, E. Kebreab, and H. Lapierre, ed. Wageningen Acad. Publ., Wageningen, the Netherlands.

Doreau, M., L. Bamière, S. Pellerin, M. Lherm, and M. Benoit. 2014. Mitigation of enteric methane for French cattle: potential extent and cost of selected actions. Anim. Prod. Sci. 54:1417-1422.

Dubeau, F., P. O. Julien, and C. Pomar. 2011. Formulating diets for growing pigs: Economic and environmental considerations. Ann. Oper. Res. 190:239-269.

EPA. 2014. Inventory of US greenhouse gas emissions and sinks: 19902012. EPA 430-R-14-003. Environ. Prot. Agency, Washington, DC.

Gelman, A., J. Carlin, H. Stern, and D. Rubin. 2004. Bayesian data analysis. Texts in Statistical Science. Chapman Hall, London, UK.

Gelman, A., and D. B. Rubin. 1992. Inference from iterative simulation using multiple sequences. Stat. Sci. 7:457-472.

Gerber, P. J., A. N. Hristov, B. Henderson, H. Makkar, J. Oh, C. Lee, R. Meinen, F. Montes, T. Ott, J. Firkins, A. Rotz, C. Dell, A. T. Adesogan, W. Z. Yang, J. M. Tricarico, E. Kebreab, G. Waghorn, J. Dijkstra, and S. Oosting. 2013. Technical options for the mitigation of direct methane and nitrous oxide emissions from livestock: A review. Animal 7:220-234.

Giordano, J., A. S. Kalantari, P. M. Fricke, M. C. Wiltbank, and V. E. Cabrera. 2012. A daily herd Markov-chain model to study the reproductive and economic impact of reproductive programs combining timed artificial insemination and estrus detection. J. Dairy Sci. 95:5442-5460.

Hendrickx, J. 2012. perturb: Tools for evaluating collinearity. R package version 2.05. Accessed Mar. 3, 2015. http://cran.r-project.org/ web/packages/perturb.

Hook, S. E., A. D. G. Wright, and B. W. McBride. 2010. Methanogens: Methane producers of the rumen and mitigation strategies. Archaea 2010:945785.

Hristov, A. N., J. Oh, J. L. Firkins, J. Dijkstra, E. Kebreab, G. Waghorn, H. P. S. Makkar, A. T. Adesogan, W. Yang, C. Lee, P. J. Gerber, B. Henderson, and J. M. Tricarico. 2013. Special topicsMitigation of methane and nitrous oxide emissions from animal operations: I. A review of enteric methane mitigation options. J. Anim. Sci. 91:5045-5069.

IPCC (Intergovernmental Panel on Climate Change). 2013. Climate Change 2013: The Physical Science Basis. Contribution of Working Group I to the Fifth Assessment Report of the Intergovernmental Panel on Climate Change. T. F. Stocker, D. Qin, G.-K. Plattner, M. Tignor, S. K. Allen, J. Boschung, A. Nauels, Y. Xia, V. Bex, and P. M. Midgley, ed. Cambridge Univ. Press, Cambridge, UK.

Jean dit Bailleul, P., J. Rivest, F. Dubeau, and C. Pomar. 2001. Reducing nitrogen excretion in pigs by modifying the traditional least-cost formulation algorithm. Livest. Prod. Sci. 72:199-211. 
Jiang, J. 2007. Linear and Generalized Linear Mixed Models and Their Applications. Springer, New York, NY.

Jones, D., and M. Tamiz. 2010. Practical Goal Programming. Springer, New York, NY.

Kebreab, E., J. A. N. Mills, L. A. Crompton, A. Bannink, J. Dijkstra, W. J. J. Gerrits, and J. France. 2004. An integrated mathematical model to evaluate nutrient partition in dairy cattle between the animal and its environment. Anim. Feed Sci. Technol. 112:131154.

Kebreab, E., A. Strathe, J. Fadel, L. Moraes, and J. France. 2010. Impact of dietary manipulation on nutrient flows and greenhouse gas emissions in cattle. Rev. Bras. Zootec. 39:458-464.

Kennedy, J. O. S. 1986. Dynamic Programming Applications to Agriculture and Natural Resources. Elsevier Appl. Sci. Publ., London, UK.

Kristensen, A. R. 1992. Optimal replacement in the dairy herd: A multi-component system. Agric. Syst. 39:1-24.

Ligges, U. 2013. BRugs: R interface to the OpenBUGS MCMC software. R package version 0.8-3. Accessed Feb. 13, 2015. http:// cran.r-project.org/web/packages/BRugs.

Martin, C., D. P. Morgavi, and M. Doreau. 2010. Methane mitigation in ruminants: From microbe to the farm scale. Animal 4:351-365.

Moe, P. W., and H. F. Tyrrell. 1979. Methane production in dairy cows. J. Dairy Sci. 62:1583-1586.

Moraes, L. E., A. B. Strathe, J. G. Fadel, D. P. Casper, and E. Kebreab. 2014. Prediction of enteric methane emissions from cattle. Glob. Chang. Biol. 20:2140-2148.

Moraes, L. E., J. E. Wilen, P. H. Robinson, and J. G. Fadel. 2012. A linear programming model to optimize diets in environmental policy scenarios. J. Dairy Sci. 95:1267-1282.

Murphy, M. R., R. L. Baldwin, and L. J. Koong. 1982. Estimation of stoichiometric parameters for rumen fermentation of roughages and concentrate diets. J. Anim. Sci. 55:411-421.

Nielsen, L. R., E. Jørgensen, A. R. Kristensen, and S. Østergaard. 2010. Optimal replacement policies for dairy cows based on daily yield measurements. J. Dairy Sci. 93:75-92.

NRC. 2001. Nutrient Requirements of Dairy Cattle. 7th ed. Natl. Acad. Press, Washington, DC.

Oenema, O. 2004. Governmental policies and measures regulating nitrogen and phosphorus from animal manure in European agriculture. J. Anim. Sci. 82(E-Suppl.):E196-E206.

Pacheco, D., G. Waghorn, and P. H. Hansen. 2014. Decreasing methane emissions from ruminants grazing forages: A fit with productive and financial realities? Anim. Prod. Sci. 54:1141-1154.

Patra, A. K. 2013. The effect of dietary fats on methane emissions, and its other effects on digestibility, rumen fermentation and lactation performance in cattle: A meta-analysis. Livest. Sci. 155:244-254.
Pomar, C., F. Dubeau, M. P. Létourneau Montminy, C. Boucher, and P. O. Julien. 2007. Reducing phosphorous concentration in pigs diets by adding an environmental objective to the traditional feed formulation algorithm. Livest. Sci. 111:16-27.

Reed, K. F., L. E. Moraes, J. G. Fadel, D. P. Casper, J. Dijkstra, J. France, and E. Kebreab. 2014. Prediction of nitrogen use in dairy cattle: A multivariate Bayesian approach. Anim. Prod. Sci. 54:1918-1926.

Romero, C., and T. Rehman. 1989. Multiple Criteria Analysis for Agricultural Decisions. Elsevier, Amsterdam, the Netherlands.

Rotz, C. A., M. S. Corson, D. S. Chianese, S. D. Hafner, and C. U. Coiner. 2013. The Integrated Farm System Model Manual Version 4.1. Pasture System and Watershed Management Research Unit, USDA Agricultural Research Service. Accessed Mar. 6, 2015. http://www.ars.usda.gov/sp2UserFiles/Place/80700500/Reference\%20Manual.pdf.

Sauvant, D., M. Eugène, S. Giger-Reverdin, H. Archimède, and M. Doreau. 2014. Relationship between CH4 and urinary N outputs in ruminants fed forages: A meta-analysis of the literature. Anim. Prod. Sci. 54:1423-1427.

Spiegelhalter, D. J., N. Best, B. P. Carlin, and A. van der Linde. 2002. Bayesian measures of model complexity and fit (with discussion). J. R. Stat. Soc., B 64:583-640.

St-Pierre, N. R., and W. R. Harvey. 1986. Incorporation of uncertainty in composition of feeds into least-cost ration models. 1. Singlechance constrained programming. J. Dairy Sci. 69:3051-3062.

Tedeschi, L. O., D. G. Fox, L. E. Chase, and S. J. Wang. 2000. Wholeherd optimization with the Cornell net carbohydrate and protein system. I. Predicting feed biological values for diet optimization with linear programming. J. Dairy Sci. 83:2139-2148.

Thomas, A., B. O'Hara, U. Ligges, and S. Sturtz. 2006. Making BUGS open. R News 6:12-17.

Tricarico, J. M., and R. L. Osborne. 2014. Promoting Dairy's Economic, Environmental, and Social Success with Cow of the Future $^{\mathrm{TM}}$ and Farm Smart ${ }^{\mathrm{TM}}$. Pages 113-115 in Proc. 2014 Penn State Dairy Cattle Nutr. Workshop. Penn State Extension, University Park, PA.

Van Soest, P. J. 1994. Nutritional Ecology of the Ruminant. 2nd ed. Cornell Univ. Press, Ithaca, NY.

Winston, W. L., and M. Venkataramanan. 2002. Introduction to Mathematical Programming: Applications and Algorithms. 4th ed. Duxbury Press, Belmont, CA. 